\title{
Identification of fibrillin 1 gene mutations in patients with bicuspid aortic valve (BAV) without Marfan syndrome
}

\author{
Guglielmina Pepe ${ }^{1,2^{*}}$, Stefano Nistri ${ }^{1,3}$, Betti Giusti ${ }^{1,2}$, Elena Sticchi ${ }^{1,2}$, Monica Attanasio ${ }^{1,2}$, Cristina Porciani ${ }^{1,2}$, \\ Rosanna Abbate ${ }^{1,2}$, Robert O Bonow ${ }^{4}$, Magdi Yacoub ${ }^{5}$ and Gian Franco Gensini $i^{1,2,6}$
}

\begin{abstract}
Background: Bicuspid aortic valve (BAV) is the most frequent congenital heart disease with frequent involvement in thoracic aortic dilatation, aneurysm and dissection. Although BAV and Marfan syndrome (MFS) share some clinical features, and some MFS patients with BAV display mutations in FBN1, the gene encoding fibrillin-1, the genetic background of isolated BAV is poorly defined.

Methods: Ten consecutive BAV patients [8 men, age range 24-42 years] without MFS were clinically characterized. BAV phenotype and function, together with evaluation of aortic morphology, were comprehensively assessed by Doppler echocardiography. Direct sequencing of each FBN1 exon with flanking intron sequences was performed on eight patients.

Results: We detected three FBN1 mutations in two patients (aged 24 and 25 years) displaying aortic root aneurysm $\geq 50 \mathrm{~mm}$ and moderate aortic regurgitation. In particular, one patient had two mutations (p.Arg2726Trp and p.Arg636Gly) one of which has been previously associated with variable Marfanoid phenotypes. The other patient showed a pArg529GIn substitution reported to be associated with an incomplete MFS phenotype.

Conclusions: The present findings enlarge the clinical spectrum of isolated BAV to include patients with BAV without MFS who have involvement of FBN1 gene. These results underscore the importance of accurate phenotyping of BAV aortopathy and of clinical characterization of BAV patients, including investigation of systemic connective tissue manifestations and genetic testing.
\end{abstract}

Keywords: Bicuspid aortic valve, Aortic disease, Aneurysm, Marfan syndrome, Fibrillin-1

\section{Background}

Bicuspid aortic valve (BAV) is the most common congenital heart disease $[1,2]$. BAV and Marfan syndrome (MFS) share some clinical features such as the increased prevalence of thoracic aortic aneurysm (TAA) and dissection (TAD), as well as overlapping histopathological features [3]. MFS is associated with mutations in the fibrillin 1 (FBN1) gene in more than $90 \%$ of patients, and less

\footnotetext{
* Correspondence: guglielmina.pepe@unifi.it

'Department of Experimental and Clinical Medicine, Section of Critical Medical Care and Medical Specialities; DENOTHE Center, University of Florence, Largo Brambilla 3, 50134 Florence, Italy

${ }^{2}$ Department of Heart and Vessels, Regional Marfan Syndrome and Related Disorders Center, Careggi Hospital, Florence, Italy

Full list of author information is available at the end of the article
}

commonly in the transforming growth factor beta receptor 2 and 1 (TGFBR2, and TGFBR1) genes [4]. While the genetic background of MFS is well described at present, that of BAV is poorly defined.

BAV has been associated with NOTCH1 gene mutations in a few cases [5], and with actin alpha 2 smooth muscle aorta (ACTA2) gene mutations (12\%) in a subgroup of patients with TAA, livedo reticularis on the upper and lower limbs, and iris flocculi [6]. Other genes are suspected to be associated, and more chromosomal loci associated to BAV have been reported $[7,8]$.

We have recently demonstrated a 4 -fold increase in the prevalence of BAV in a large cohort of unrelated MFS patients (12 BAV in 257 MFS, 4.7\%) with respect 
to the general population screened by echocardiography including primary school students in Italy $(0.5 \%)$, detecting FBN1 mutations in 2 out of 3 subjects who consented to undergo DNA mutation analysis [9]. These findings are consistent with data showing decreased FBN1 mRNA or protein content in a subgroup of BAV patients [10], which suggest that FBN1 may be one of the genes associated with BAV.

To date, however, the demonstration of FBN1 mutations in patients with BAV is lacking. Thus, we screened for FBN1 mutations in the selected patients with BAV and thoracic aortic dilation not fulfilling the clinical criteria for MFS.

\section{Methods}

\section{Ethical statements}

The local Ethical Committee of the Medicine Faculty of Florence approved the study protocols and participants provided their written informed consent to participate in this study.

\section{Subjects}

Among the 432 patients with thoracic aortic dilatation, aneurysm, or dissection consecutively referred to the Center for Marfan Syndrome (Careggi Hospital, Florence, Italy) between 2001 and 2011, 22 were affected by BAV and aortic enlargement (aortic diameter $\geq 40 \mathrm{~mm}$ ), of whom 12 had also MFS [9]. In the other ten patients, the diagnosis of MFS was excluded according to both the old and the revised Ghent criteria [4,11], and these patients constitute the subject of the present study. We also screened a control cohort of 200 unrelated individuals recruited from the same geographical area (160 male; mean age $33.2 \pm 8.5$ years) for the presence of the genetic variants identified in the BAV patients with aortic enlargement. The controls were also evaluated for the presence and familial history of connective tissue disorders, BAV and aortic dilatation/dissection. The presence of BAV and or aortic dilatation/dissection was excluded in controls by echocardiography.

\section{Echocardiographic methods}

All echocardiographic measurements had been made by a senior cardiologist (C.P.). BAV was diagnosed when only two cups were unequivocally identified in systole and diastole in the short axis view with a clear "fishmouth" appearance during systole as previously described $[1,12]$. Aortic dimensions were assessed at end-diastole in the parasternal long-axis view at four levels by the leading edge method $[1,12,13]$ and Z-scores were calculated according to age-adjusted nomograms [13]. For patients who had undergone aortic surgery, still-frame photographs and/or available videos were also reviewed to verify and confirm the diagnosis of BAV. Patients for whom aortic valve morphology was indeterminate were considered as having tricuspid aortic valves. Aortic or mitral regurgitation were graded by multiple criteria combining color Doppler and continuous wave Doppler signals, and aortic valve stenosis was graded by peak aortic valve velocity [1].

\section{DNA extraction, polymerase chain reaction and direct sequencing}

Genomic DNA was extracted from peripheral venous blood using FlexiGene Kit (Qiagen, Germany). The 65 exons of $F B N 1$ gene with the intronic flanking regions were amplified by polymerase chain reaction (PCR) [14]. PCR products were directly sequenced [14].

DNA samples from 200 healthy individuals were screened to determine whether the mutations identified in this study were present in a control population by direct sequencing of the exons in which the three mutations were identified. Prediction of the effect of mutations was performed by Polyphen-2 (http://genetics.bwh.harvard.edu/ pph2/), Sorting Tolerant From Intolerant (SIFT, http://sift. jcvi.org) and MuPro (http://www.igb.uci.edu/ baldig/mutation.html) algorithms.

\section{Results}

All patients [ 8 men and 2 women, age range $24-42$ years] were Italian. Two of them (P8 and P10) (Table 1) had MASS syndrome (an acronym for myopia, mitral valve prolapse, aortic dilatation, skeleton features, skin features); most displayed systemic features such as pectus excavatum, scoliosis, pes planus, cutaneous striae, mitral valve prolapse and myopia (Table 1). All had fusion of the right and left coronary aortic valve cusps, and 8 of 10 patients had maximum aortic enlargement at the level of the aortic root and not at the ascending aorta.

\section{FBN1 gene mutation analysis}

Mutations analysis was performed on 8 of the $10 \mathrm{pa}$ tients as P7 and P8 did not give consent to undergo mutation screening analysis. FBN1 mutations were detected in two patients (P1 and P2).

P1 had a c.1586G > A, p.Arg529Gln mutation that represents a basic to polar neutral charge change in exon 12 (cbEGF-like 03 domain) (Figure 1). In P2 a double mutation was detected: a c.1906A > G mutation (p.Arg636Gly basic to apolar substitution) and a c.8176C $>\mathrm{T}$ mutation (p.Arg2726Trp causing a basic to apolar change); the first located in exon 15 (cbEGF-like 06 domain), the second in exon $64(\mathrm{COOH}$ unique region) (Figure 1$)$. The three mutations were not present in 400 alleles among Italian controls. No mutations were detected in the other 6 patients.

\section{Discussion}

To the best of our knowledge, this is the first study reporting pathogenetic fibrillin 1 mutations in patients with BAV and aortic dilatation/aneurysm in whom MFS 
Table 1 Clinical and molecular characteristics of the 10 studied patients

\begin{tabular}{|c|c|c|c|c|c|c|c|c|c|c|c|}
\hline \multirow{2}{*}{$\begin{array}{l}\text { Patients } \\
\text { ID }\end{array}$} & \multirow{2}{*}{$\begin{array}{l}\text { Age at diagnosis/referred } \\
\text { to our center (years) }\end{array}$} & \multirow[b]{2}{*}{ Sex } & \multicolumn{9}{|c|}{ Diagnostic criteria } \\
\hline & & & BAV morphology & $\begin{array}{l}\text { MAS: diameter } \\
(\mathrm{mm}) / \mathrm{site}\end{array}$ & BAV hemodynamics & MVP & Eye EL & $\begin{array}{l}\text { Systemic } \\
\text { features }\end{array}$ & $\begin{array}{c}\text { Systemic } \\
\text { features score }\end{array}$ & Family history & $\begin{array}{c}\text { FBN1 } \\
\text { mutations }\end{array}$ \\
\hline P1 & $15 / 24$ & M & $R L$ & $50 / A \circ R$ & AR moderate & - & - & - & 0 & TAA & Arg529Gln \\
\hline P2 & $19 / 25$ & M & $R L$ & $57 / A \circ R$ & AR moderate & + & - & MVP, My & 2 & - & $\begin{array}{l}\text { Arg636Gly } \\
\text { Arg2726Trp }\end{array}$ \\
\hline P3 & $35 / 40$ & M & $R L$ & $45 / A \circ R$ & - & - & - & My, PE, Sc, Th+ & 4 & - & - \\
\hline P4 & $27 / 40$ & $\mathrm{~F}$ & $R L$ & $41 / A \circ R$ & AR mild & + & - & MVP, PP, CS & 3 & TAA/AAA & - \\
\hline P5 & $17 / 24$ & M & $R L$ & $47 / \mathrm{Asc} A$ & - & - & - & SC, PP, CS & 3 & - & - \\
\hline P6 & $40 / 40$ & M & $R L$ & $44 / A \circ R$ & - & - & - & $P E, C S$, facies & 3 & - & - \\
\hline P7 & $42 / 42$ & M & $R L$ & Prothesic tube & - & - & - & CS & 1 & - & na \\
\hline P8 & $31 / 31$ & M & $R L$ & $42 / \mathrm{AscA}$ & - & + & - & $M V P, P E, P C, P P, C S$ & 6 & BAV & na \\
\hline P9 & $24 / 24$ & M & $R L$ & 40/AoR & - & - & - & $P E, K y, C S, M y$ & 4 & TAA & - \\
\hline P10 & $31 / 31$ & $\mathrm{~F}$ & $\mathrm{RL}$ & $48 / A \circ R$ & AR mild & + & - & MVP, CS, DE, PP, SC & 5 & - & - \\
\hline
\end{tabular}

$\mathrm{ID}=$ identification number; $\mathrm{BAV}=$ bicuspid aortic valve; $\mathrm{MAS}=$ maximal aortic size; $\mathrm{M}=$ male; $\mathrm{F}=$ female; $\mathrm{MVP}=$ mitral valve prolapse; $\mathrm{RL}=$ fusion of right and left coronary leaflets; $\mathrm{EL}=$ ectopia lentis; AoR = aortic root; $A R=$ aortic regurgitation; $\mathrm{Asc}=$ = Ascending aorta; Systemic features are reported and quoted according to new Ghent criteria (Loeys' et al. 2010); $C S=c$ cutaneous Striae; $E L=$ ectopia lentis; $H D=$ hindfoot deformities; My = myopia; $\mathrm{PE}=$ pectus excavatum, ; PP = pes planus; $\mathrm{SC}=$ scoliosis; $K y=$ kyphosis; $\mathrm{Th}+=$ positive thumb sign; + = present; $-=$ absent; na = not analyzed. 
(A)

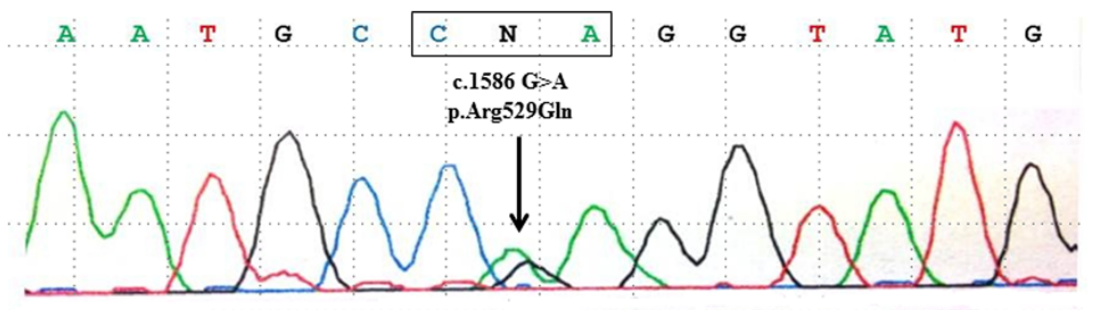

$\left(\mathbf{B}_{1}\right)$

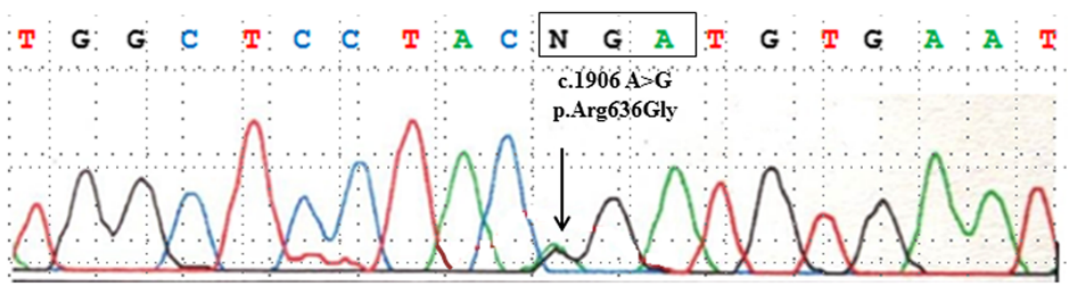

$\left(\mathbf{B}_{2}\right)$

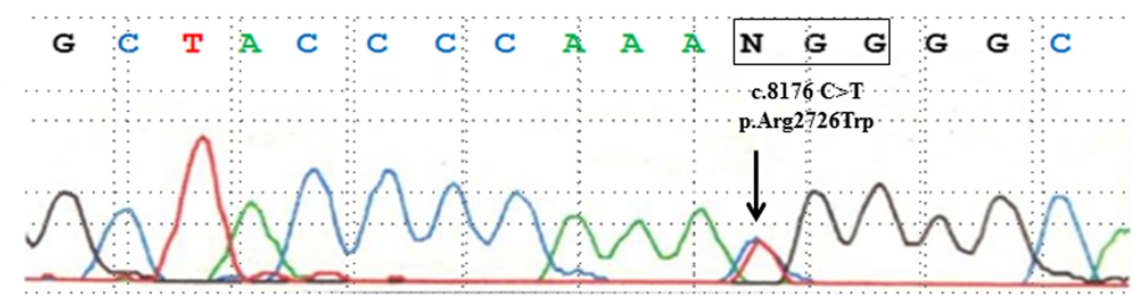

Figure 1 Identification of FBN1 mutations in BAV patients. A: Sequence chromatogram showing c.1586 G>A (p. Arg529Gln) mutation, identified in P1 patient. B1/B2: Sequence chromatograms showing c.1906 A > G (p. Arg636Gly) and c.8176C > T (p. Arg2726Trp) mutations, identified in P2 patients. Arrows indicate the locations of the point mutations.

and other more severe type 1 fibrillinopathies were clinically excluded according to the updated Ghent criteria [4].

The mutations detected in two unrelated patients are all arginine substitutions. The Arg529Gln mutation detected in P1 is reported at the UMD-FBN1 database (http://www. umd.be/FBN1/4DACTION/WV/2451) in a male proband of France geographic origin with an incomplete MFS phenotype. Unfortunately, no further information on BAV occurrence in this patient is available. Moreover, a single nucleotide substitution in the same codon causing a preterminal stop codon was previously described in a Norwegian patient displaying a classic Marfan phenotype with ectopia lentis, thoracic aorta dilatation and systemic features [15]. According to Polyphen-2 and MuPro, the Arg529Gln mutation is probably damaging and contributes to decreased protein stability. P2 carried two mutations, one of which (Arg2726Trp) has been previously associated with variable clinical phenotypes, including mitral valve prolapse and myopia [14], isolated skeletal features [16], combined skeletal and ocular manifestations [17], mild skeletal abnormalities [18]; and a family in which the mutation appeared incompletely penetrant [19]. The Arg2726Trp mutation was reported in one chromosome in 1000Genomes and NHLBI Exome Variant Server databases as rs61746008 (http://www.1000genomes.org/ and http://evs.gs.washington.edu/EVS/). The other mutation (Arg636Gly) identified in P2 has never been reported in the literature, although another single nucleotide substitution responsible for a different aminoacid change at the same codon (Arg636Ile) in a MFS patient with aortic root dilatation, ectopia lentis and minor involvement of skeleton was previously described [17]. According to SIFT, both the Arg2726Trp and Arg636Gly mutations are classified as damaging, with decreased protein stability as evaluated in silico by MuPro.

It is unknown at present if the two mutations at the FBN1 locus identified in our patient are in cis, on the same chromosome, or in trans. The infrequent presence of double mutations has been reported in many human gene-causing diseases such as hypertrophic cardiomyopathy $[20,21]$ and arrhythmias associated with the lamin $\mathrm{A} / \mathrm{C}$ (LMNA) gene [22].

The detection of $F B N 1$ point mutations in patients with BAV with aortic dilatation/aneurysm but without MFS adds to the striking clinical heterogeneity of type I fibrillinopathies to include a small number of patients bearing the most common congenital heart disease. These data also provide further evidence of the heterogeneity of the BAV syndrome [12], with demonstration that aortic dilatation/aneurysm develops in a subgroup of patients as a manifestation of an inherited connective tissue disorder, including FBN1 mutations in a minority of patients. It is noteworthy that the two patients carrying the mutations 
displayed a family history of TAA in one and MVP in the other, without systemic features which were otherwise prevalent in the remaining subjects. Moreover, both had aortic aneurysm size attaining the threshold for surgery notwithstanding the young age $[23,24]$, with the largest diameter localized at the level of the sinuses of Valsalva, which is the less prevalent phenotype of aortic dilatation in BAV individuals [1,25]. Della Corte, et al., first named this pattern as "root phenotype" [25] and have subsequently demonstrated that it may be a marker of more severe aortopathy warranting closer surveillance [26]. Interestingly, 8 out of our 10 patients displayed this phenotype, in association with a certain degree of systemic characteristics suggestive of a connective tissue disorder. Finally, the 2 patients bearing FBN1 mutations had significant aortic regurgitation, which is a powerful predictor of loss of aortic medial elastic fibers in patients with ascending aortic aneurysms and aortic valve disease [27]. These findings call for greater focus on the BAV-related cardiovascular abnormalities rather than on the MFS-like systemic features, which may well coexist and warrant investigation in BAV patients in general, but are not associated with the FBN1 mutations identified in the present study. On the other hand, these FBN1 mutations do not completely fulfill the definition of the major criterion for MFS according to the revised Ghent criteria because they have never been detected in Marfan patients with TAA [4]. Therefore our two BAV/TAA patients did not achieve the diagnosis of MFS.

The FBN1 gene has been previously associated with various conditions, including MFS, neonatal MFS, Shprintzen-Goldberg syndrome, marfanoid neonatal progeroid syndrome, familial arachnodactyly, ectopia lentis, isolated ascending aortic aneurysm and dissection, aortic root dilatation without dissection, skeletal and skin abnormalities (MASS phenotype), Marfan-like syndromes, autosomal dominant Weill-Marchesani syndrome (WMS), mitral valve prolapse, and sclerodermia. Recently, mutations in the FBN1 gene were reported in two other syndromes [28,29]. The interfamilial clinical heterogeneity at the FBN1 locus is further characterized by a striking intrafamilial variability (OMIM*134797).

Contrasting data have been reported regarding the genetic background of BAV-related aortopathy. A decrease in FBN1 mRNA and protein has been demonstrated in some BAV patients suggesting a possible involvement of FBN1 with BAV [10]. Moreover, single nucleotide polymorphisms (SNPs) spread in the area of the FBN1 gene, which predispose to TAA, have been reported [30]. On the other hand, other investigators have screened BAV patients for mutations in FBN1, TGFBR2, and TGFBR1 genes and failed to detect any mutation, concluding that the $F B N 1$ gene is not, or only rarely, associated with BAV [31]. More recently, a mutation in the TGFBR2 gene was reported in a patient classified as aortic dilatation/aneurysm but otherwise not well defined clinically [32]. Another recent study, comparing gene expression in subjects with BAV and tricuspid aortic valves, reported an increase of FBN1 mRNA only in the subjects with tricuspid aortic valves [33]. Thus, it is conceivable that BAV represents the phenotypic manifestation of many distinct clinical outliers underlined by genetic, molecular, and structural anomalies that do not follow a common path [7].

At present we cannot exclude a coincidence of a common trait such as BAV in males and a rare trait like MFS in our patients. In fact, a limitation of our study is the lack of genomic DNA from parents and other relatives of the two patients carrying mutations in FBN1 gene to demonstrate their segregation with BAV in the two families. Another limitation of our study is the use of transthoracic echocardiography for the ascertainment of BAV rather than advanced imaging methods. However, the echocardiographic evaluation of our patients was performed by an operator with a wide experience in BAV diagnosis.

Our findings may have relevant clinical implications in the future, if confirmed by larger studies. Although multiple similarities have been shown between MFS and BAV patients, recent improvements in knowledge regarding the natural history of the aortopathy in BAV [34-36] have raised concerns regarding the direct application of surgical criteria adopted in MFS patients to those with BAV and aortic dilatation/aneurysm [37,38]. On the other hand, cardiovascular events are considerable in patients with FBN1 mutations and remain so throughout life, with men appearing to be at higher risk for an aortic event than women [39]. While we acknowledge that the size of the present study and its retrospective nature do not allow conclusions regarding the indications for surgery, our findings support the need of future studies aimed to characterize BAV patients with aortic dilatation/aneurysm on the basis of their aortic phenotype and other clinical stigmata of connective tissue disorders, eventually performing genetic testing when appropriate. Whether such an approach would result in a different outcome, thus affecting therapeutic choices in patients with BAV and aortic dilatation/aneurysm, should be a pivotal aim of such future research.

\section{Conclusions}

The novel implication of the present findings is the need of a multidisciplinary approach (including internal medicine, medical genetics, cardiology, ophthalmology, cardiovascular surgery, orthopaedic, and molecular biology experts) in the global assessment and management of patients with BAV. Due to the high prevalence of this disorder and its multispecialty requirements, our findings suggest a tailored diagnostic and therapeutic approach, which should be addressed in future prospective studies. 
In conclusion, this current findings expand the concept that $\mathrm{BAV}$ is a heterogenous disorder with a wide spectrum of clinical manifestations. Beyond the common phenotype of isolated BAV and the previously reported association of BAV in MFS patients [9], we described BAV patients in whom the clinical diagnosis of MFS has been excluded, carrying mutations in FBN1 gene. These data also expands the clinical spectrum of the type 1 fibrillinopathies to include BAV. These results underscore the importance of accurate clinical characterization of BAV aortopathy, including investigation of systemic connective tissue manifestations and genetic testing.

\section{Competing interests}

The authors declare that they have no competing interest.

\section{Authors' contributions}

All authors satisfy the requirements for authorship and contributorship. Conception and design: GP, SN, ROB, MY, RA, GFG; Analysis and interpretation BG, ES, MA; Data Collection GP, SN, CP; Writing the article GP, SN, BG, ES; Critical revision of the article GP, SN, ROB, RA, MY, GFG; Final approval of the article GP, SN, BG, ES, MA, CP, ROB, MY, RA, GFG; Obtaining funding RA GFG. All authors read and approved the final manuscript.

\section{Acknowledgements}

This work was supported by grants from Ente Cassa di Risparmio di Firenze to Fiorgen Foundation, Florence, Italy, and from University of Florence (ex60\%).

\section{Author details \\ 'Department of Experimental and Clinical Medicine, Section of Critical Medical Care and Medical Specialities; DENOTHE Center, University of Florence, Largo Brambilla 3, 50134 Florence, Italy. ${ }^{2}$ Department of Heart and Vessels, Regional Marfan Syndrome and Related Disorders Center, Careggi Hospital, Florence, Italy. ${ }^{3}$ Cardiology Service, CMSR Veneto Medica, AltavillaVicentina, Italy. ${ }^{4}$ Department of Medicine, Northwestern University, Chicago, IL, USA. ${ }^{5}$ Heart Science Centre, Imperial College, London, UK. ${ }^{6}$ S. Maria agli Ulivi Center, Fondazione Don Carlo Gnocchi, Onlus, IRCCS, Florence, Italy.}

Received: 12 December 2013 Accepted: 14 February 2014 Published: 24 February 2014

\section{References}

1. Nistri S, Basso C, Marzari C, Mormino P, Thiene G: Frequency of bicuspid aortic valve in young male conscripts by echocardiogram. Am J Cardiol 2005, 96:718-721.

2. Siu SC, Silversides CK: Bicuspid aortic valve disease. J Am Coll Cardiol 2010, $55: 2789-2800$

3. Nataatmadja M, West M, West J, Summers K, Walker P, Nagata M, Watanabe T: Abnormal extracellular matrix protein transport associated with increased apoptosis of vascular smooth muscle cells in Marfan syndrome and bicuspid aortic valve thoracic aortic aneurysm. Circulation 2003, 108(Suppl 1):|1329-||334.

4. Loeys BL, Dietz HC, Braverman AC, Callewaert BL, De Backer J, Devereux RB, Hilhorst-Hofstee Y, Jondeau G, Faivre L, Milewicz DM, Pyeritz RE, Sponseller PD, Wordsworth P, De Paepe AM: The revised Ghent nosology for the Marfan syndrome. J Med Genet 2010, 47:476-485.

5. Garg V, Muth AN, Ransom JF, Schluterman MK, Barnes R, King IN, Grossfeld PD, Srivastava D: Mutations in NOTCH1 cause aortic valve dis-ease. Nature 2005, 437:270-274.

6. Guo DC, Pannu H, Tran-Fadulu V, Papke CL, Yu RK, Avidan N, Bourgeois S, Estrera AL, Safi HJ, Sparks E, Amor D, Ades L, McConnell V, Willoughby CE, Abuelo D, Willing M, Lewis RA, Kim DH, Scherer S, Tung PP, Ahn C, Buja LM, Raman CS, Shete SS, Milewicz DM: Mutations in smooth muscle alpha-actin (ACTA2) lead to thoracic aortic aneurysms and dissections. Nat Genet 2007, 39:1488-1493.
7. El-Hamamsy I, Yacoub MH: A measured approach to managing the aortic root in patients with bicuspid aortic valve disease. Curr Cardiol Rep 2009, 11:94-100.

8. Laforest B, Nemer M: Genetic insights into bicuspid aortic valve formation. Cardiol Res Pract 2012, 2012:180297.

9. Nistri S, Porciani MC, Attanasio M, Abbate R, Gensini GF, Pepe G: Association of Marfan syndrome and bicuspid aortic valve: frequency and outcome. Int J Cardiol 2012, 155:324-325.

10. Fedak PW, de Sa MP, Verma S, Nili N, Kazemian P, Butany J, Strauss BH, Weisel RD, David TE: Vascular matrix remodeling in patients with bicuspid aortic valve malformations: implications for aortic dilatation. $J$ Thorac Cardiovasc Surg 2003, 126:797-806.

11. De Paepe A, Devereux RB, Dietz HC, Hennekam RC, Pyeritz RE: Revised diagnostic criteria for the Marfan syndrome. Am J Med Genet 1996, 62:417-426.

12. Nistri S, Grande-Allen J, Noale M, Basso C, Siviero P, Maggi S, Crepaldi G, Thiene G: Aortic elasticity and size in bicuspid aortic valve syndrome. Eur Heart J 2008, 29:472-479.

13. Roman MJ, Devereux RB, Kramer-Fox R, O'Loughlin J: Two-dimensional echocardiographic aortic root dimensions in normal children and adults. Am J Cardiol 1989, 64:507-512.

14. Attanasio M, Lapini I, Evangelisti L, Lucarini L, Giusti B, Porciani M, Fattori R, Anichini C, Abbate R, Gensini G, Pepe G: FBN1 mutation screening of patients with Marfan syndrome and related disorders: detection of 46 novel FBN1 mutations. Clin Genet 2008, 74:39-46.

15. Rand-Hendriksen S, Tjeldhorn L, Lundby R, Semb SO, Offstad J, Andersen K, Geiran O, Paus B: Search for correlations between FBN1 genotype and complete Ghent phenotype in 44 unrelated Norwegian patients with Marfan syndrome. Am J Med Genet A 2007, 143A:1968-1977.

16. Milewicz DM, Grossfield J, Cao SN, Kielty C, Covitz W, Jewett T: A mutation in FBN1 disrupts profibrillin processing and results in isolated skeletal features of the Marfan syndrome. J Clin Invest 1995, 95:2373-2378.

17. Arbustini E, Grasso M, Ansaldi S, Malattia C, Pilotto A, Porcu E, Disabella E, Marziliano N, Pisani A, Lanzarini L, Mannarino S, Larizza D, Mosconi M, Antoniazzi E, Zoia MC, Meloni G, Magrassi L, Brega A, Bedeschi MF, Torrente I, Mari F, Tavazzi L: Identification of sixty-two novel and twelve known FBN1 mutations in eighty-one unrelated probands with Marfan syndrome and other fibrillinopathies. Hum Mutat 2005, 26:494.

18. Van Dijk FS, Hamel BC, Hilhorst-Hofstee Y, Mulder BJ, Timmermans J, Pals G, Cobben JM: Compound-heterozygous Marfan syndrome. Eur J Med Genet 2009, 52:1-5.

19. Buoni S, Zannolli R, Macucci F, Ansaldi S, Grasso M, Arbustini E, Fois A: The FBN1 (R2726W) mutation is not fully penetrant. Ann Hum Genet 2004, 68:633-638.

20. van Rijsingen IA, Hermans-van Ast JF, Arens YH, Schalla SM, de DieSmulders CE, van den Wijngaard A, Pinto YM: Hypertrophic cardiomyopathy family with double-heterozygous mutations; does disease severity suggest double heterozygosity? Neth Heart J 2009, 17:458-463.

21. Girolami F, Ho CY, Semsarian C, Baldi M, Will ML, Baldini K, Torricelli F, Yeates L, Cecchi F, Ackerman MJ, Olivotto I: Clinical features and outcome of hypertrophic cardiomiopathy associated with triple sarcomere protein gene mutations. J Am Coll Cardiol 2010, 55:1444-1453.

22. Marsman RF, Bardai A, Postma AV, Res JC, Koopmann TT, Beekman L, van der Wal AC, Pinto YM, Lekanne Deprez RH, Wilde AA, Jordaens $L$, Bezzina CR: A complex double deletion in LMNA underlies progressive cardiac conduction disease, atrial arrhythmias, and sudden death. Circ Cardiovasc Genet 2011, 4:280-287.

23. Bonow RO, Carabello BA, Chatterjee K, de Leon AC, Jr FDP, Freed MD, Gaasch WH, Lytle BW, Nishimura RA, O'Gara PT, O'Rourke RA, Otto CM, Shah PM, Shanewise JS, Smith SC Jr, Jacobs AK, Adams CD, Anderson JL, Antman EM, Fuster V, Halperin JL, Hiratzka LF, Hunt SA, Lytle BW, Nishimura R, Page RL, Riegel B: ACC/AHA 2006 guidelines for the management of patients with valvular heart disease: a report of the American College of Cardiology/American Heart Association Task Force on Practice Guidelines (Writing committee to develop guidelines for the management of patients with valvular heart disease). J Am Coll Cardiol 2006, 48:e1-e148.

24. Vahanian A, Baumgartner H, Bax J, Butchart E, Dion R, Filippatos G, Flachskampf F, Hall R, lung B, Kasprzak J, Nataf P, Tornos P, Torracca L, Wenink $A$ : Guidelines on the management of valvular heart disease: the task force on the management of valvular heart disease of the European society of cardiology. Eur Heart J 2007, 28:230-268. 
25. Della Corte A, Bancone C, Quarto C, Dialetto G, Covino FE, Scardone M, Caianiello G, Cotrufo M: Predictors of ascending aortic dilatation with bicuspid aortic valve: a wide spectrum of disease expression. Eur J Cardiothorac Surg 2007, 31:397-404.

26. Della Corte A, Bancone C, Buonocore M, Dialetto G, Covino FE, Manduca S, Scognamiglio G, D'Oria V, De Feo M: Pattern of ascending aortic dimensions predicts the growth rate of the aorta in patients with bicuspid aortic valve. JACC Cardiovasc Imaging 2013, 6:1301-1310.

27. Roberts WC, Vowels TJ, Ko JM, Filardo G, Hebeler RF Jr, Henry AC, Matter GJ, Hamman BL: Comparison of the structure of the aortic valve and ascending aorta in adults having aortic valve replacement for aortic stenosis versus for pure aortic regurgitation and resection of the ascending aorta for aneurysm. Circulation 2011, 123:896-903.

28. Takenouchi T, Hida M, Sakamoto Y, Torii C, Kosaki R, Takahashi T, Kosaki K: Severe congenital lipodystrophy and a progeroid appearance: mutation in the penultimate exon of FBN1 causing a recognizable phenotype. Am J Med Genet A 2013, 161:3057-3062.

29. Wilson $B T$, Jensen $S A$, McAnulty CP, Brennan P, Handford PA: Juvenile idiopathic arthritis, mitral valve prolapse and a familial variant involving the integrin-binding fragment of FBN1. Am J Med Genet A 2013, 161A:2047-2051.

30. Lemaire SA, McDonald ML, Guo DC, Russell L, Miller CC 3rd, Johnson RJ, Bekheirnia MR, Franco LM, Nguyen M, Pyeritz RE, Bavaria JE, Devereux R, Maslen C, Holmes KW, Eagle K, Body SC, Seidman C, Seidman JG, Isselbacher EM, Bray M, Coselli JS, Estrera AL, Safi HJ, Belmont JW, Leal SM, Milewicz DM: Genome-wide association study identifies a susceptibility locus for thoracic aortic aneurysms and aortic dissections spanning FBN1 at 15q21.1. Nat Genet 2011, 43:996-1000.

31. Arrington CB, Sower CT, Chuckwuk N, Stevens J, Leppert MF, Yetman AT, Bowles NE: Absence of TGFBR1 and TGFBR2 mutations in patients with bicuspid aortic valve and aortic dilation. Am J Cardiol 2008, 102:629-631.

32. Girdauskas E, Schulz S, Borger MA, Mierzwa M, Kuntze T: Transforming growth factor-beta receptor type II mutation in a patient with bicuspid aortic valve disease and intra operative aortic dissection. Ann Thorac Surg 2011, 91:e70-e71.

33. Folkersen L, Wågsäter D, Paloschi V, Jackson V, Petrini J, Kurtovic S, Maleki S, Eriksson MJ, Caidahl K, Hamsten A, Michel JB, Liska J, Gabrielsen A, FrancoCereceda A, Eriksson P: Unraveling divergent gene expression profiles in bicuspid and tricuspid aortic valve patients with thoracic aortic dilatation: the ASAP study. Mol Med 2011, 17:1365-1373.

34. Michelena HI, Khanna AD, Mahoney D, Margaryan E, Topilsky Y, Suri RM, Eidem B, Edwards WD, Sundt TM 3rd, Enriquez-Sarano M: Incidence of aortic complications in patients with bicuspid aortic valves. JAMA 2011, 306:1104-1112.

35. McKellar SH, MacDonald RJ, Michelena HI, Connolly HM, Sundt TM 3rd: Frequency of cardiovascular events in women with a congenitally bicuspid aortic valve in a single community and effect of pregnancy on events. Am J Cardiol 2011, 107:96-99.

36. Tzemos N, Therrien J, Yip J, Thanassoulis G, Tremblay S, Jamorski MT, Webb GD, Siu SC: Outcomes in adults with bicuspid aortic valves. JAMA 2008, 300:1317-1325.

37. Sundt TM 3rd: Replacement of the ascending aorta in bicuspid aortic valve disease: where do we draw the line? J Thorac Cardiovasc Surg 2010 140(6 Suppl):S41-S44.

38. Roberts WC: Prophylactic replacement of a dilated ascending aorta at the time of aortic valve replacement of a dysfunctioning congenitally unicuspid or bicuspid aortic valve. Am J Cardiol 2011, 108:1371-1372.

39. Détaint D, Faivre L, Collod-Beroud G, Child AH, Loeys BL, Binquet C, Gautier E, Arbustini E, Mayer K, Arslan-Kirchner M, Stheneur C, Halliday D, Beroud C, Bonithon-Kopp C, Claustres M, Plauchu H, Robinson PN, Kiotsekoglou A, De Backer J, Adès L, Francke U, De Paepe A, Boileau C, Jondeau G: Cardiovascular manifestations in men and women carrying a FBN1 mutation. Eur Heart J 2010, 31:2223-2229.

doi:10.1186/1471-2350-15-23

Cite this article as: Pepe et al: Identification of fibrillin 1 gene mutations in patients with bicuspid aortic valve (BAV) without Marfan syndrome. BMC Medical Genetics 2014 15:23.

\section{Submit your next manuscript to BioMed Central and take full advantage of:}

- Convenient online submission

- Thorough peer review

- No space constraints or color figure charges

- Immediate publication on acceptance

- Inclusion in PubMed, CAS, Scopus and Google Scholar

- Research which is freely available for redistribution 